\title{
A cross-sectional study of peripartum blood transfusion in the Eastern Cape, South Africa
}

\author{
K van den Berg, ${ }^{1} \mathrm{MB}$ ChB, MMedSci; E M Bloch, ${ }^{2,3} \mathrm{MD}$, MS; A S Aku, ${ }^{4,5} \mathrm{MBBS}$, MPhil, MCH; M Mabenge, ${ }^{6,7}$ MB ChB, MMed; \\ D V Creel, ${ }^{8}$ MS; G J Hofmeyr ${ }^{7,9-12}$ DSc; E L Murphy, ${ }^{3,13}$ MD, MPH
}

${ }^{1}$ Medical Division, South African National Blood Service, Johannesburg, South Africa

${ }^{2}$ Department of Pathology, School of Medicine, Johns Hopkins University, Baltimore, Md, USA

${ }^{3}$ Blood Systems Research Institute, San Francisco, Calif, USA

${ }^{4}$ Department of Obstetrics and Gynaecology, Cecilia Makiwane Hospital, Mdantsane, South Africa

${ }^{5}$ Department of Obstetrics and Gynaecology, Frere Hospital, East London, South Africa

${ }^{6}$ Department of Obstetrics and Gynaecology, Dora Nginza Hospital, Port Elizabeth, South Africa

${ }^{7}$ Department of Obstetrics and Gynaecology, Faculty of Health Sciences, Walter Sisulu University, East London, South Africa

${ }^{8}$ RTI International, Rockville, Md, USA

${ }^{9}$ Effective Care Research Unit, East London, South Africa

${ }^{10}$ Department of Obstetrics and Gynaecology, Faculty of Health Sciences, University of the Witwatersrand, Johannesburg, South Arica

${ }^{11}$ Department of Obstetrics and Gynaecology, Faculty of Health Sciences, Fort Hare University, Alice, South Africa

${ }^{12}$ Eastern Cape Department of Health, East London, South Africa

${ }^{13}$ Departments of Laboratory Medicine and Epidemiology/Biostatistics, University of California, San Francisco, Calif, USA

Corrresponding author: $K$ van den Berg (karin.vandenberg@sanbs.org.za)

\begin{abstract}
Background. Obstetric haemorrhage $(\mathrm{OH})$ remains a major contributor to maternal morbidity and mortality. Blood transfusion is critical in $\mathrm{OH}$ management; yet, data on peripartum transfusion are lacking. A pilot study reported high rates of peripartum transfusion in a sample of South African (SA) hospitals, which was independently associated with HIV status.

Objectives. To assess the incidence of peripartum transfusion in a sample of Eastern Cape, SA hospitals to evaluate generalisability of preceding study findings.

Methods. Hospital chart reviews were conducted of all deliveries at three large regional hospitals from February to June 2013. Additional clinical data were collected for patients who sustained $\mathrm{OH}$ and/or were transfused.

Results. A total of 7234 women were enrolled in the study; 1988 (27.5\%) were HIV-positive. Of the 767 HIV-positive women with a CD4 count $<350$ cells $/ \mu \mathrm{L}, 86.0 \%$ were on full antiretroviral therapy and $9.9 \%$ received drugs for prevention of mother-to-child transmission. The overall transfusion rate was $3.2 \%$, with significant variability by hospital: Frere Hospital (1.5\%), Dora Nginza Hospital (3.8\%) and Cecilia Makiwane Hospital (4.6\%). The number of red blood cell units per transfused patient and per delivery varied significantly by hospital. Bivariate analysis showed significant association between transfusion and HIV status. In a multivariate analysis, controlling for $\mathrm{OH}$, age, mode of delivery, gestational age, parity and birthweight, this association (odds ratio 1.45; 95\% confidence interval $0.78-2.71$ ) was no longer significant.

Conclusion. These findings confirm high rates of peripartum transfusion in SA. While this can be possibly ascribed to variability in practice and patient profile, variation in care and improvement in HIV treatment should be considered.
\end{abstract}

S Afr Med J 2016;106(11):1103-1109. DOI:10.7196/SAMJ.2016.v106i11.10870

In South Africa (SA), as is the case globally, obstetric haemorrhage $(\mathrm{OH})$ remains a leading contributor to maternal mortality and morbidity despite being the focus of related research and health interventions. ${ }^{[1-3]}$ Delayed recognition of risk factors for $\mathrm{OH}$ and failure to provide effective peripartum care directly and adversely affect maternal outcomes. This is most notable in resource-poor settings, particularly where rural geography, ineffective referral and transportation systems compound risk associated with obstetric emergencies. ${ }^{[4,5]}$ Consequently, $\mathrm{OH}$ and high rates of blood transfusion prescribed for $\mathrm{OH}$ are frequently encountered in resourcepoor settings, which is evident in SA. ${ }^{[6,7]}$

A shortfall in the provision of blood transfusion is estimated to contribute to a quarter of maternal deaths in sub-Saharan Africa. ${ }^{[8]}$ Specific to SA, postpartum haemorrhage continued to contribute significantly to maternal deaths over the last reported triennium (2011 - 2013). ${ }^{[3]}$ While data are available for $\mathrm{OH}$ and maternal mortality, those pertaining to blood use in this population are lacking. For example, despite availability of published transfusion guidelines in SA in the obstetric setting, compliance with these guidelines is largely unknown. ${ }^{[9]}$ Obstetric blood transfusion places a significant burden on local blood transfusion services in SA, whereby improved data are necessary for planning. More specifically, an understanding of risk factors for peripartum transfusion can identify deficiencies of care, thus informing rational intervention. Finally, $\sim 30 \%$ of pregnant women in SA are HIV-positive; ${ }^{[10]}$ in these patients associated antenatal anaemia may place them at risk of peripartum blood transfusion.

Despite strained transfusion inventories in SA, a previous study demonstrated high rates of blood transfusion compared with high-resource settings, even though there were comparable rates of $\mathrm{OH} .{ }^{[11]}$ We investigated the risk factors underlying peripartum transfusion in semi-rural SA, thereby complementing the earlier study that had been conducted in urban SA hospitals. ${ }^{[1]}$ We also gathered contemporary data on the proportion of the obstetric population that is HIV-positive as well as antiretroviral treatment 
regimens in use to evaluate the level of compliance with standard guidelines.

\section{Methods \\ Study design and subjects}

We conducted a cross-sectional, hospital chart review of all deliveries at three large regional hospitals in the Eastern Cape, SA: Dora Nginza Hospital (DNH) in Port Elizabeth, Frere Hospital (FH) in East London, and Cecilia Makiwane Hospital (CMH) in Mdantsane. The study was conducted over 4.5 months (February - June 2013). Ethical approval was obtained from the University of California, San Francisco (UCSF), USA, the SA National Blood Service (SANBS), Johannesburg, the Eastern Cape Department of Health, East London, and RTI International, Rockville, USA. The study was performed under an approved waiver of consent for the collection of retrospective data without personal identifiers.

All three hospitals are part of the public sector healthcare system in SA, which provides medical services to low-income and uninsured, predominantly black (African) and coloured (mixed population group) patients. Each of the hospitals provides a broad range of routine obstetric services, and also serves as a referral centre for the surrounding district hospitals and midwife obstetric units.

The study adopted a similar approach to that used by the Recipient Epidemiology and Donor Evaluation Study-III (REDS-III) Obstetric Hemorrhage Pilot Study. ${ }^{[1]}$ Limited data were collected for all peripartum obstetric patients who had an index hospitalisation at a participating hospital. Comprehensive data were collected for the subset of patients who sustained $\mathrm{OH}$ and/or were transfused. Eligible patients were identified through daily review of the admission registers for the various wards and theatres, coupled with direct communication with the local blood bank and ward staff. The data were collected using the Obstetric Hemorrhage Audit Tool (OHAT), which was adapted from the instrument used in the previous study ${ }^{[11]}$ Volume of blood loss was not routinely recorded at CMH and FH. The data were subsequently transferred to RTI International, the data co-ordinating centre, for quality control and analysis.

\section{Definitions}

We used the same definitions as those used in the previous study. ${ }^{[1]}$ $\mathrm{OH}$ was defined as any obstetric-related haemorrhage occurring in the peripartum period, the latter defined as 48 hours prior, during or post delivery. In accordance with the World Health Organization (WHO)'s definition, peripartum haemorrhage refers to blood loss $\geq 500 \mathrm{~mL}$ for vaginal deliveries or $\geq 1000 \mathrm{~mL}$ for caesarean sections. All women who delivered at at least 26 weeks' gestation were included in the study, independent of stillbirths or early neonatal deaths (pregnancyrelated haemorrhage prior to 26 weeks gestation is typically managed by gynaecology departments in SA). Transfusion was defined as having received a transfusion of any allogeneic blood product, e.g. red blood cells (RBCs), platelets, plasma and/or cryoprecipitate; however, only RBC transfusions were used for calculating transfusion parameters. Booked refers to patients who had access to antenatal care, while unbooked refers to those who had not accessed any antenatal care during the index pregnancy. The most recently measured haemoglobin prior to the delivery admission was recorded as the antenatal haemoglobin. Similarly, the pre- and post-haemoglobin values refer to the last haemoglobin level prior to and the first haemoglobin level after the transfusion, respectively. The $\delta$-haemoglobin is the difference between the post- and pre-haemoglobin levels and is used to calculate the haemoglobin increment per transfused RBC unit.

HIV status and HIV-related medication regimens were recorded. Prevention of mother-to-child transmission (РMTCT) refers to the use of limited antiretroviral monotherapy during the antenatal period, followed by additional antiretroviral treatment (ART) peripartum, administered specifically to mitigate against vertical HIV transmission. ART refers to the use of triple-therapy antiretroviral drugs.

\section{Statistical analysis}

Standard summary statistics were used to generate counts and percentages for categorical data and distributions for continuous variables. For categorical data, counts and percentages for single variables and combinations of variables were produced using $\chi^{2}$ tests of significance. For the continuous data, distributions were examined individually and stratified by covariates, using $t$-tests to establish differences between means.

Mutlivariate modelling was limited to data from DNH and was conducted using logistic regression. A larger set of variables was initially considered. The model was refined using backwards elimination at the $p=0.05$ level to retain variables. Once a set of variables was identified, interactions were investigated. The models were subjected to the Hosmer-Lemeshow test for goodness of fit. SAS 9.3 (TS1M2) (SAS Institute Inc., USA) with enhanced analytical product SAS/ STAT 12.1 (SAS Institute Inc., USA) was used for the data manipulation and analysis; R version 3.0.1 - Good Sport (R Core Team, USA) was used for the data visualisation.

\section{Results}

A total of 7234 women were enrolled in the study (Table 1). The majority of the participants were aged 19 - 29 years and $9.3 \%$ were $\leq 18$ years. The racial distribution was predominantly black and coloured. The women were mostly gravida 1 or 2 and para 0 or 1 . More than $95 \%$ of the women had received antenatal care. The majority of births were normal vaginal deliveries, but there were high rates of caesarean section; $1.7 \%$ of births occurred before arrival at the hospital. Overall, $27.5 \%$ of the patients were HIV-positive and prevalence varied slightly by site.

A total of 234 (3.2\%) women were transfused. Bivariate analysis demonstrated significant variability in transfusion incidence by hospital: $\mathrm{FH}(1.5 \%), \mathrm{DNH}(3.8 \%)$ and $\mathrm{CMH}(4.6 \%)(p<0.00001)$ (Table 2). Significantly increased transfusion rates were noted with increased parity; also among unbooked patients (7.1\%) compared with booked patients (3.0\%). Transfusion varied significantly by birthweight, where the highest rates occurred at the extremes. Gestational age had a significant inverse association with transfusion.

In a multivariable analysis of data from $\mathrm{DNH}$, the only hospital with recorded blood loss, $\mathrm{OH}$ was significantly associated with caesarean section (odds ratio (OR) 3.17; 95\% confidence interval (CI) 2.16 - 4.67), positive HIV status (OR 1.64; 95\% CI 1.12 - 2.39), gestational age $\leq 34$ weeks (OR 2.63; 95\% CI $1.24-5.55)$ and high birthweight (>3 $770 \mathrm{~g})$ (OR 3.09; 95\% CI 1.35 - 7.06). In a separate model of transfusion, which was also limited to $\mathrm{DNH}$, only $\mathrm{OH}$ (OR 62.14; 95\% CI 35.90 - 107.54), and to a lesser degree increased parity (4+ v. 0; OR 3.31; 95\% CI $1.08-10.16$ ), as well as decreased gestational age ( 34 - 36 weeks v. $\geq 41$ weeks; OR 4.32; $95 \%$ CI 1.96 9.49; 37 weeks v. $\geq 41$ weeks; OR 2.58 ; $95 \%$ CI $0.99-6.74 ; 38$ weeks v. $\geq 41$ weeks; OR $3.30 ; 95 \%$ CI $1.62-6.72$ ) were associated with receipt of a blood transfusion. Caesarean section patients were less likely to receive a transfusion after controlling for $\mathrm{OH}$ (OR 0.44; 95\% CI 0.26 $0.74)$. Although bivariate analysis showed higher transfusion rates among HIV-positive patients, this association (OR 1.45; 95\% CI 0.78 - 2.71) was not significant after controlling for $\mathrm{OH}$, age category, mode of delivery, birthweight, parity and gestational age.

Mean antenatal haemoglobin differed significantly $(p<0.001)$ between the respective hospitals (Fig. 1). Although there was not a significant difference in the mean pre- or post-transfusion haemoglobin levels across hospitals (Table 3), there was a significant mean differ- 
ence $(p=0.0302)$ in $\delta$-haemoglobin levels at $\mathrm{DNH}(1.08 \mathrm{~g} / \mathrm{dL}), \mathrm{FH}(1.45 \mathrm{~g} / \mathrm{dL})$ and $\mathrm{CMH}$ $(1.99 \mathrm{~g} / \mathrm{dL})$. The mean number of RBC units per transfused patient and per delivery differed significantly by hospital; transfused patients received an average of $1.93 \mathrm{U}$ at $\mathrm{DNH}$, $2.05 \mathrm{U}$ at $\mathrm{FH}$, and $2.61 \mathrm{U}$ at $\mathrm{CMH}(p=0.0079)$. $\mathrm{CMH}$ had the highest mean number of units transfused per delivery $(0.12)$, followed by $\mathrm{DNH}(0.07)$ and $\mathrm{FH}(0.03)(p<0.0001)$.

Among HIV-positive women, the CD4 count distribution did not differ between the hospitals $(p=0.97)$. However, the hospitals differed in the proportion of women who received ART $(p<0.0001)$. Of those patients with a CD4 $<350$ cells $/ \mu \mathrm{L}$ (old guidelines), FH had the highest ART coverage (91.0\% full ART; 6.4\% PMTCT), followed by DNH (86.6\% ART; 8.7\% PMTCT) and CMH (79.8\% ART; 15.5\% PMTCT) (Table 4). For women with a CD4 $\geq 350$ cells $/ \mu \mathrm{L}, \mathrm{DNH}$ (62.1\%) had the highest ART coverage, followed by $\mathrm{CMH}(45.2 \%)$ and $\mathrm{FH}(10.2 \%$; $p<0.0001)$. HIV-negative women had a mean haemoglobin of $11.03 \mathrm{~g} / \mathrm{dL}$ compared with $10.67 \mathrm{~g} / \mathrm{dL}$ in HIV-positive women $(p<0.001)$ (Fig. 2). Of the 234 women who were transfused, $82(35.0 \%)$ were HIVpositive.

\section{Discussion}

This study describes the incidence of peripartum transfusion at three hospitals in the Eastern Cape, SA. In contrast to the four hospitals that participated in the earlier $\mathrm{OH}$ pilot study, the Eastern Cape hospitals are comparatively under-resourced, have less academic support and are located in a more rural setting, lending greater generalisability to the findings in the preceding study. ${ }^{[11]}$ Estimated blood loss was incompletely documented at two of the three hospitals, precluding detailed analysis of $\mathrm{OH}$. However, at $\mathrm{DNH}$, where $\mathrm{OH}$ was routinely recorded, the $\mathrm{OH}$ incidence was $4.6 \%$ (data not shown), which is higher than that reported in both the USA and the first pilot study. ${ }^{[11-13]}$ Similarly, the overall transfusion rate was $3.2 \%$, exceeding that reported in the previous study ${ }^{[11]}$ and markedly higher than that reported for the USA and other high-resource settings ${ }^{[12,13]}$ Furthermore, there was significant variation $(1.5-4.6 \%)$ in the transfusion rates among the participating hospitals. While this could reflect differences in the patient populations, variability in clinical practice (individual and/or institutional) cannot be excluded. Variability in practice might also explain differences in HIV and ART coverage.

The variability in transfusion practice among the participating hospitals is possibly multifactorial. As observed in other developing countries, ${ }^{[14]}$ this variability may be ascribed
Table 1. Characteristics of the study population

\begin{tabular}{|c|c|c|c|c|}
\hline Characteristics & All subjects, $\boldsymbol{n}$ (\%) & $\mathrm{CMH}, n(\%)$ & DNH, $n(\%)$ & FH, $n(\%)$ \\
\hline All subjects & $7234(100)$ & $1641(100)$ & $3191(100)$ & $2402(100)$ \\
\hline \multicolumn{5}{|l|}{ Age (years) } \\
\hline$\leq 18$ & $676(9.3)$ & $173(10.5)$ & $281(8.8)$ & $222(9.2)$ \\
\hline $19-24$ & $2298(31.8)$ & $517(31.5)$ & $996(31.2)$ & $785(32.7)$ \\
\hline $25-29$ & $1763(24.4)$ & $364(22.2)$ & $792(24.8)$ & $607(25.3)$ \\
\hline $30-34$ & $1358(18.8)$ & $298(18.2)$ & $622(19.5)$ & $438(18.2)$ \\
\hline $35-39$ & $797(11.0)$ & $186(11.3)$ & $355(11.1)$ & $256(10.7)$ \\
\hline$\geq 40$ & $292(4.0)$ & $88(5.4)$ & $126(3.9)$ & $78(3.2)$ \\
\hline Missing & $50(0.7)$ & $15(0.9)$ & $19(0.6)$ & $16(0.7)$ \\
\hline \multicolumn{5}{|l|}{ Race } \\
\hline Black & $6149(85.0)$ & 1623 (98.9) & $2392(75.0)$ & $2134(88.8)$ \\
\hline Coloured & $867(12.0)$ & $5(0.3)$ & $712(22.3)$ & $150(6.2)$ \\
\hline Asian & $19(0.3)$ & $0(0.0)$ & $10(0.3)$ & $9(0.4)$ \\
\hline White & $80(1.1)$ & $0(0.0)$ & $19(0.6)$ & $61(2.5)$ \\
\hline Missing & $119(1.6)$ & $13(0.8)$ & $58(1.8)$ & $48(2.0)$ \\
\hline \multicolumn{5}{|c|}{ Gravida (including current pregnancy) } \\
\hline 1 & $2683(37.1)$ & $653(39.8)$ & $1117(35.0)$ & $913(38.0)$ \\
\hline 2 & $2259(31.2)$ & $488(29.7)$ & $1011(31.7)$ & $760(31.6)$ \\
\hline 3 & $1392(19.2)$ & $306(18.6)$ & $625(19.6)$ & $461(19.2)$ \\
\hline $4+$ & $851(11.8)$ & $183(11.2)$ & $414(13.0)$ & $254(10.6)$ \\
\hline Missing & $49(0.7)$ & $11(0.7)$ & $24(0.8)$ & $14(0.6)$ \\
\hline \multicolumn{5}{|l|}{ Para (before current delivery) } \\
\hline 0 & $3010(41.6)$ & $717(43.7)$ & $1297(40.6)$ & $996(41.5)$ \\
\hline 1 & $2297(31.8)$ & $487(29.7)$ & $1037(32.5)$ & $773(32.2)$ \\
\hline 2 & $1225(16.9)$ & $274(16.7)$ & $528(16.5)$ & $423(17.6)$ \\
\hline 3 & $439(6.1)$ & $108(6.6)$ & $192(6.0)$ & $139(5.8)$ \\
\hline $4+$ & $210(2.9)$ & $40(2.4)$ & $113(3.5)$ & $57(2.4)$ \\
\hline Missing & $53(0.7)$ & $15(0.9)$ & $24(0.8)$ & $14(0.6)$ \\
\hline \multicolumn{5}{|l|}{ Prenatal visit } \\
\hline Booked & $6882(95.1)$ & $1554(94.7)$ & $2993(93.8)$ & $2335(97.2)$ \\
\hline Unbooked & $266(3.7)$ & $72(4.4)$ & $143(4.5)$ & $51(2.1)$ \\
\hline Missing & $86(1.2)$ & $15(0.9)$ & $55(1.7)$ & $16(0.7)$ \\
\hline \multicolumn{5}{|l|}{ Type of delivery } \\
\hline Vaginal & $3988(55.1)$ & $756(46.1)$ & $1775(55.6)$ & $1457(60.7)$ \\
\hline Caesarean section & $3057(42.3)$ & $811(49.4)$ & $1373(43.0)$ & $873(36.3)$ \\
\hline Born before arrival & $122(1.7)$ & $64(3.9)$ & $1(0.0)$ & $57(2.4)$ \\
\hline Missing & $67(0.9)$ & $10(0.6)$ & $42(1.3)$ & $15(0.6)$ \\
\hline \multicolumn{5}{|l|}{ HIV status } \\
\hline Missing/unknown & $110(1.5)$ & $25(1.5)$ & $35(1.1)$ & $50(2.1)$ \\
\hline Negative & $5136(71.0)$ & $1109(67.6)$ & $2295(71.9)$ & $1732(72.1)$ \\
\hline Positive & $1988(27.5)$ & $507(30.9)$ & $861(27.0)$ & $620(25.8)$ \\
\hline $\mathrm{CD} 4 \geq 350$ cells $/ \mu \mathrm{L}$ & $885(12.2)$ & $241(14.7)$ & $369(11.6)$ & $275(11.4)$ \\
\hline $\mathrm{CD} 4 \geq 200-349$ cells $/ \mu \mathrm{L}$ & $463(6.4)$ & $129(7.9)$ & $197(6.2)$ & $137(5.7)$ \\
\hline $\mathrm{CD} 4<200$ cells $/ \mu \mathrm{L}$ & $304(4.2)$ & $84(5.1)$ & $124(3.9)$ & $96(4.0)$ \\
\hline CD4 missing/unknown & $336(4.6)$ & $53(3.2)$ & $171(5.4)$ & $112(4.7)$ \\
\hline
\end{tabular}

in part to differences in clinical practice Clinical transfusion practice is influenced by individual physician and by institution. by the presence of transfusion policy and/or 
Table 2. Bivariate analysis of risk factors for transfusion among all women $\left(\chi^{2} p\right.$-values)

\begin{tabular}{|c|c|c|c|c|c|c|c|}
\hline Risk factors & $\begin{array}{l}\text { No transfusion, } \\
n(\%)\end{array}$ & $\begin{array}{l}\text { Transfusion, } \\
n(\%)\end{array}$ & $p$-value & Risk factors & $\begin{array}{l}\text { No transfusion, } \\
n(\%)\end{array}$ & $\begin{array}{l}\text { Transfusion, } \\
n(\%)\end{array}$ & $p$-value \\
\hline All subjects & $7000(96.8)$ & $234(3.2)$ & & HIV status & & & 0.0301 \\
\hline Antenatal haemoglobin (g/dL) & & & $<0.0001$ & Missing/unknown & $98(89.1)$ & $12(10.9)$ & \\
\hline Mean & 10.95 & 10.17 & & Negative & $4996(97.3)$ & $140(2.7)$ & \\
\hline Median & 11.0 & 10.5 & & Positive & $1906(95.9)$ & $82(4.1)$ & \\
\hline Hospital & & & $<0.0001$ & $\mathrm{CD} 4 \geq 350$ cells $/ \mu \mathrm{L}$ & $290(95.4)$ & $14(4.6)$ & \\
\hline $\mathrm{CMH}$ & $1565(95.4)$ & $76(4.6)$ & & CD4 $200-349$ cells $/ \mu \mathrm{L}$ & $441(95.2)$ & $22(4.8)$ & \\
\hline DNH & $3070(96.2)$ & $121(3.8)$ & & $\mathrm{CD} 4<200$ cells $/ \mu \mathrm{L}$ & $851(96.2)$ & $34(3.8)$ & \\
\hline $\mathrm{FH}$ & $2365(98.5)$ & $37(1.5)$ & & CD4 missing/unknown & $324(96.4)$ & $12(3.6)$ & \\
\hline Age (weeks) & & & 0.8855 & Birthweight (g) & & & $<0.0001$ \\
\hline$\leq 18$ & $652(96.4)$ & $24(3.6)$ & & $\leq 2000$ & $690(93.8)$ & $46(6.3)$ & \\
\hline $19-24$ & $2221(96.6)$ & $77(3.4)$ & & $2001-2450$ & $698(95.7)$ & $31(4.3)$ & \\
\hline $25-29$ & $1712(97.1)$ & $51(2.9)$ & & $2451-2700$ & $677(97.0)$ & $21(3.0)$ & \\
\hline $30-34$ & $1313(96.7)$ & $45(3.3)$ & & $2701-2900$ & $701(98.0)$ & $14(2.0)$ & \\
\hline $35-39$ & $773(97.0)$ & $24(3.0)$ & & $2901-3050$ & $728(98.5)$ & $11(1.5)$ & \\
\hline$\geq 40$ & $285(97.6)$ & $7(2.4)$ & & $3051-3200$ & $750(97.8)$ & $17(2.2)$ & \\
\hline Missing & $44(88.0)$ & $6(12.0)$ & & $3201-3350$ & $641(97.1)$ & $19(2.9)$ & \\
\hline Race & & & 0.2259 & $3351-3510$ & $676(97.4)$ & $18(2.6)$ & \\
\hline Black & $5955(96.8)$ & $194(3.2)$ & & $3511-3770$ & $697(97.8)$ & $16(2.2)$ & \\
\hline Coloured & $834(96.2)$ & $33(3.8)$ & & $\geq 3771$ & $675(95.9)$ & $29(4.1)$ & \\
\hline Asian & $19(100.0)$ & $0(0.0)$ & & Missing & $67(84.8)$ & $12(15.2)$ & \\
\hline White & $80(100.0)$ & $0(0.0)$ & & Gestational age (weeks) & & & $<0.0001$ \\
\hline Missing & $112(94.1)$ & $7(5.9)$ & & $\leq 33$ & $697(93.8)$ & $46(6.2)$ & \\
\hline Gravida & & & 0.0789 & $34-36$ & $1000(95.4)$ & $48(4.6)$ & \\
\hline 1 & $2600(96.9)$ & $83(3.1)$ & & 37 & $514(97.9)$ & $11(2.1)$ & \\
\hline 2 & $2192(97.0)$ & $67(3.0)$ & & 38 & $1198(96.5)$ & $44(3.5)$ & \\
\hline 3 & $1354(97.3)$ & $38(2.7)$ & & 39 & $859(97.9)$ & $18(2.1)$ & \\
\hline $4+$ & $812(95.4)$ & $39(4.6)$ & & 40 & $2220(98.1)$ & $42(1.9)$ & \\
\hline Missing & $42(85.7)$ & $7(14.3)$ & & $\geq 41$ & $323(98.5)$ & $5(1.5)$ & \\
\hline Para (before current delivery) & & & 0.0493 & Missing & $189(90.4)$ & $20(9.6)$ & \\
\hline 0 & $2917(96.9)$ & $93(3.1)$ & & & & & \\
\hline
\end{tabular}

guidelines, in addition to the extent to which they are mandated in the hospital. Current SA obstetric transfusion guidelines recommend antenatal transfusion for patients with symptomatic anaemia and/or with haemoglobin values $<6 \mathrm{~g} / \mathrm{dL}$, or emergency caesarean section for patients with haemoglobin values $<8 \mathrm{~g} / \mathrm{dL}^{.}{ }^{[15]}$ Furthermore, the guidelines recommend maintaining a haemoglobin level $>8 \mathrm{~g} / \mathrm{dL}$ in patients with $\mathrm{OH} .{ }^{[9]}$ Importantly, the implementation of, and adherence to, transfusion guidelines can serve to reduce the number of transfusions without a concomitant increase in morbidity or mortality ${ }^{[16]}$ Differences in the hospital population may also contribute to the variability in blood utilisation. For example, a higher gravidity, parity and proportion of unbooked cases were noted at $\mathrm{DNH}$ and $\mathrm{CMH}$ compared with $\mathrm{FH}$. Similar variation in blood utilisation by population has previously been reported in other settings. ${ }^{[1]}$ The impact of blood utilisation and transfusion practice on patient outcomes in the obstetric setting is an active research focus. ${ }^{[16]}$

Several authors have suggested that the global increase in $\mathrm{OH}$ is due to an increased incidence of uterine atony. The latter is associated with increased parity, high birthweight and caesarean sections, ${ }^{[13,17]}$ 


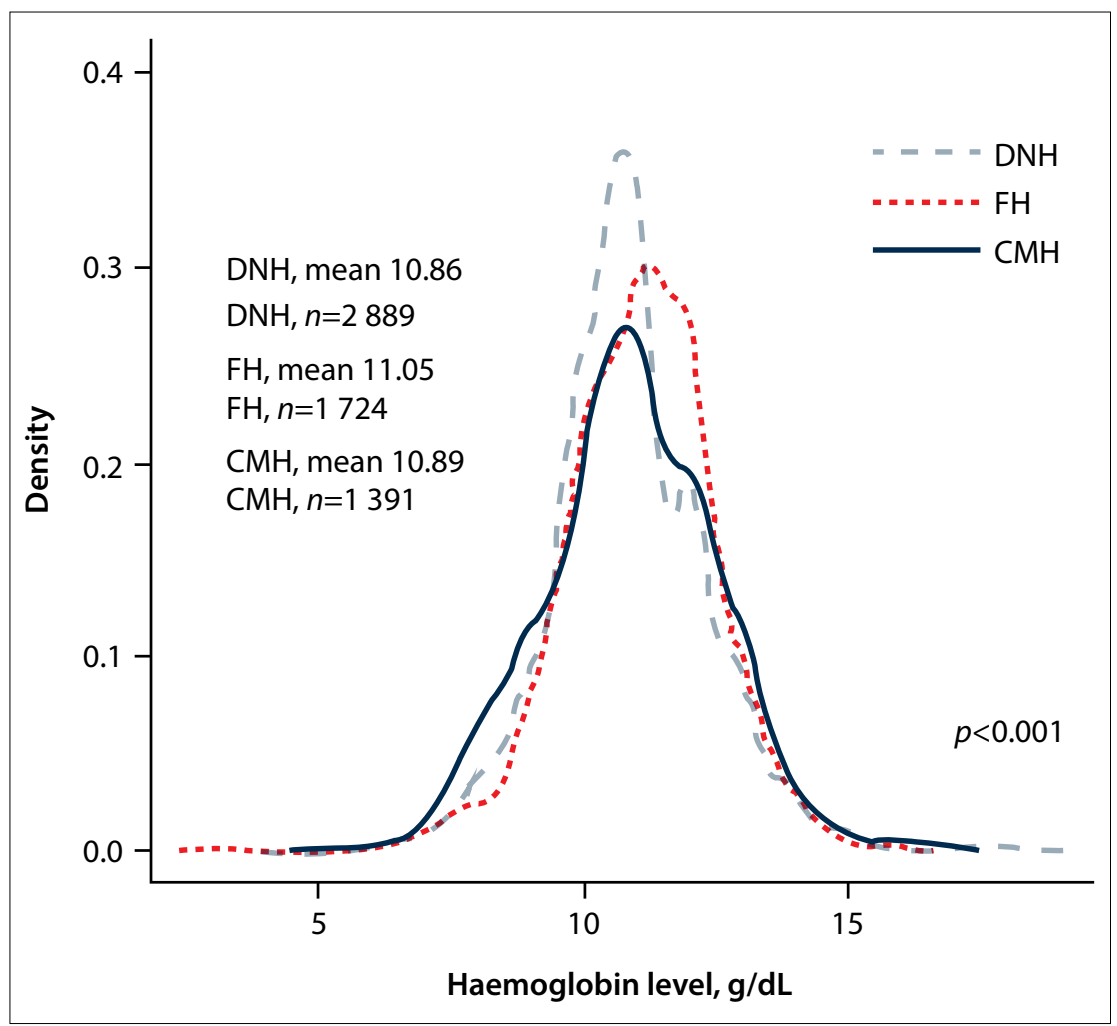

Fig. 1. Haemoglobin distribution by hospital.

Table 3. Red blood cell transfusions and haemoglobin values by hospital.

\begin{tabular}{lllll}
\hline Characteristics & CMH & DNH & FH & p-value \\
\hline Antenatal Hb $(n)$ & 1391 & 2889 & 1724 & \\
$\quad$ Mean (median) & $10.89(10.9)$ & $10.86(10.8)$ & $11.05(11.0)$ & $<0.0001$ \\
Pre-transfusion Hb* $(n)$ & 57 & 118 & 32 & \\
$\quad$ Mean (median) & $6.97(6.6)$ & $7.55(7.3)$ & $7.12(6.7)$ & 0.1036 \\
Post-transfusion Hb* $(n)$ & 57 & 118 & 32 & \\
$\quad$ Mean (median) & $8.96(8.7)$ & $8.64(8.5)$ & $8.57(8.4)$ & 0.3463 \\
$\delta$-Hb* (post-pre) $(n)$ & 57 & 118 & 32 & \\
$\quad$ Mean (median) & $1.99(2.2)$ & $1.08(1.3)$ & $1.45(1.7)$ & 0.0302 \\
Red blood cells (U)/transfused patient ${ }^{*}(n)$ & 76 & 121 & 37 & \\
$\quad$ Mean (median) & $2.61(2)$ & $1.93(2)$ & $2.05(2)$ & 0.0079 \\
Red blood cells $(\mathrm{U})$ transfused/delivery $(n)$ & 1641 & 3191 & 2402 & \\
$\quad$ Mean (median) & $0.12(0)$ & $0.07(0)$ & $0.03(0)$ & $<0.0001$ \\
${ }^{*}$ Transfused patients only. & & & &
\end{tabular}

all of which were notably also associated with increased rates of transfusion in our study. However, the association between increasing age, parity/gravidity and $\mathrm{OH}$ has not been consistently demonstrated, ${ }^{[13,17]}$ as was the case in our study where increased transfusion rates were noted with increasing parity but not with increasing age. Age and parity are associated, which may account for the variable findings with regard to the association between increasing age, parity and $\mathrm{OH}$ noted in various publications. ${ }^{[13,17]} \mathrm{Lack}$ of or poor access to (or failure to access) antenatal care, in this instance denoted by booked $\mathrm{v}$. unbooked cases, is a known predictor of poor maternal and fetal outcomes, ${ }^{[18]}$ and is reflected in our findings by the higher transfusion rate among unbooked patients. This further underscores the importance of antenatal care in the prevention of obstetric complications.

The study showed that HIV remains highly prevalent among pregnant women in SA. Almost a third of our patients were HIVpositive, of whom fewer than half $(45 \%)$ had CD4 counts $>350$ cells $/ \mu \mathrm{L}$ and $\sim 15 \%$ had CD 4 counts $<200$ cells $/ \mu \mathrm{L}$, reflecting a high burden of advanced HIV disease. The
SA guidelines for PMTCT changed during the course of the study, recommending full ART for all pregnant women, independent of viral load or CD4 count. Germane to our results, the majority of the patients (63\%) were on full ART coverage, with a larger proportion of the patients on full ART coverage than in the preceding pilot study, suggesting a rapid adoption of the new guidelines. At $\mathrm{DNH}$, multivariable analysis showed that caesarean section, positive HIV status and high birthweight were independently associated with $\mathrm{OH}$. However, after controlling for $\mathrm{OH}$, the odds of transfusion in HIV-positive patients while similar to that of the preceding pilot study - did not attain statistical significance. This discrepancy could reflect the change to the SA guidelines; specifically, ART is associated with improvement of anaemia, which may blunt the effect of HIV on risk of transfusion. Moreover, the relatively small number of participants included in the single hospital analysis may have limited power to detect a significant HIV effect.

In a meta-analysis of HIV and the risk of obstetric complications, Calvert and Ronsmans $^{[19]}$ found that HIV-positive women had twice the odds of antepartum haemorrhage, but no association with postpartum haemorrhage. Early in the epidemic, caesarean section was recommended for patients who were HIV-positive, potentially confounding an association, given increased risk of bleeding with operative care. The significantly lower haemoglobin values observed in HIV-positive patients (also evident in the preceding study), reflect unaddressed antenatal anaemia in this population. Even if not sufficiently severe to warrant transfusion, the low haemoglobin values, noted in patients at all three hospitals, confer an increased risk of peripartum transfusion, given that anaemia renders those patients less able to tolerate normal blood loss associated with delivery.

\section{Study limitations}

The study had limitations. Foremost was the lack of routine recording of the estimated blood loss during delivery at two of the participating hospitals. Second, despite selecting three comparatively rural and less academic hospitals, this study still fails to provide insight into the rates of $\mathrm{OH}$ and associated transfusion practice at primary level hospitals. It is conceivable that $\mathrm{OH}$ rates may differ significantly in primary level hospitals, owing to the existing barriers to antenatal and high-risk obstetric care. ${ }^{[4,5]}$ However, it would be logistically challenging to replicate this study at the primary care level, given the smaller number of deliveries and therefore 


\begin{tabular}{lllll}
\multicolumn{6}{l}{ Table 4. Characteristics of HIV-positive patients by hospital } & & \\
\hline Characteristics & CMH, $\boldsymbol{n}(\%)$ & DNH, $\boldsymbol{n}(\%)$ & FH, $\boldsymbol{n}(\%)$ & $\boldsymbol{p}$-value \\
\hline $\begin{array}{l}\text { HIV-positive patients } \\
\text { CD4 count }(\text { cells/ } \mu \mathrm{L})\end{array}$ & $507(100)$ & $861(100)$ & $620(100)$ & \\
$\quad$ Missing & $53(10.5)$ & $171(19.9)$ & $112(18.1)$ & 0.9748 \\
$<200$ & $84(16.6)$ & $124(14.4)$ & $96(15.5)$ & \\
200 - 349 & $129(25.4)$ & $197(22.9)$ & $137(22.1)$ & \\
$\geq 350$ & $241(47.5)$ & $369(42.9)$ & $275(44.4)$ & \\
HIV treatment $(\mathrm{CD} 4<350$ cells/ $\mu \mathrm{L})$ & & & & 0.0021 \\
Missing & $5(2.3)$ & $11(3.4)$ & $6(2.5)$ & \\
ART & $170(79.8)$ & $278(86.6)$ & $212(91.0)$ & \\
None & $5(2.3)$ & $4(1.2)$ & $0(0.0)$ & \\
PMTCT & $33(15.5)$ & $28(8.7)$ & $15(6.4)$ & \\
HIV treatment $(\mathrm{CD} 4 \geq 350$ cells/ $\mu \mathrm{L})$ & & & & $<0.0001$ \\
Missing & $7(2.9)$ & $20(5.4)$ & $4(1.4)$ & \\
ART & $109(45.2)$ & $229(62.1)$ & $28(10.2)$ & \\
None & $0(0.0)$ & $9(2.4)$ & $0(0.0)$ & \\
PMTCT & $125(51.9)$ & $111(30.1)$ & $243(88.4)$ & \\
& & & &
\end{tabular}

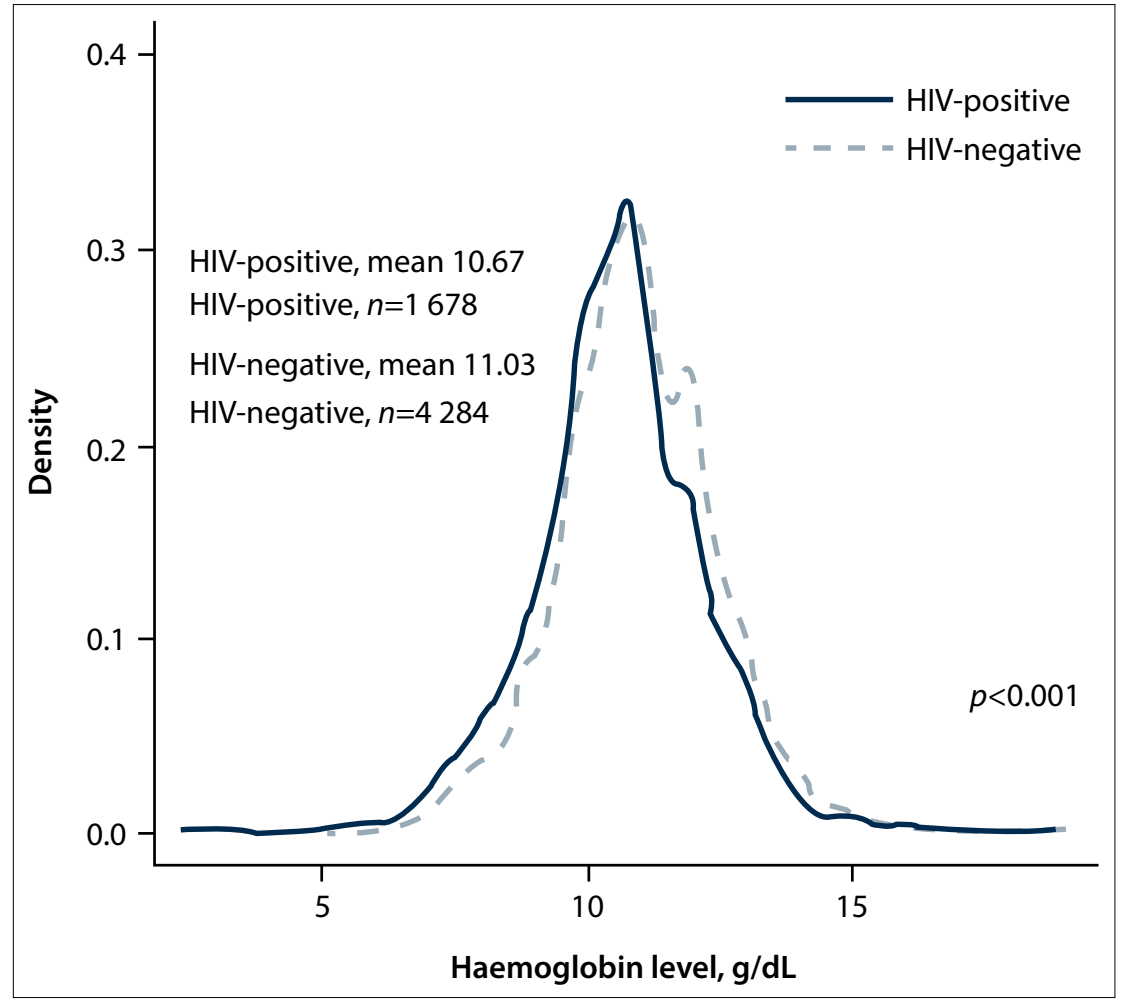

Fig. 2. Haemoglobin distribution by HIV status.

$\mathrm{OH}$ and transfusions at any one hospital. Because high-risk pregnancies are referred upward, the majority of transfusions in SA occur in secondary and tertiary hospitals, supporting our approach.

Despite the limitations, this study offers insight into the variability in contemporary obstetric transfusion practice. It has contributed to the identification of antecedent risk factors for and the obstetric and current transfusion management of $\mathrm{OH}$, enabling the implementation of systematic improvement in regional transfusion practice. The study also provides further validation of the methods and OHAT audit form, such that similar studies might be undertaken in other settings. Finally, while the HIV clinical data confirm enduring high rates of HIV in this population, they also suggest the successful implementation of the new HIV treatment guidelines.

\section{Conclusion}

This study demonstrates the high rates of peripartum blood transfusion in SA despite rates of $\mathrm{OH}$ that approximate those reported in high-income countries. Blood inventories in SA are strained, given the clinical demand (average blood reserve of 4.4 days; $\mathrm{T}$ Brits, SANBS, personal communication, 2016). The findings suggest that variability in transfusion practice contributes to high rates of transfusion. Published national obstetric transfusion guidelines are available in SA; our findings suggest the need to promote the guidelines (e.g. using focused training) and review compliance. ${ }^{[15]}$ Knowledge of blood use is imperative to the SA transfusion services to ensure an adequate blood supply, thus directly impacting a key Millennium Development Goal to reduce maternal mortality by $75 \%$.

Acknowledgements. The authors wish to thank Ms R Solwandle and the staff of the Effective Care Research Unit at the Frere and Cecilia Makiwane hospitals, for their invaluable contribution to the study. We are also grateful to the medical and nursing personnel at Dora Nginza, Cecilia Makiwane, and Frere hospitals for their support. Funding. Financial support was received from the National Heart Lung and Blood Institute Recipient Epidemiology and Donor Evaluation Study (REDS-III), research contract HHSN268201100009I.

1. Bates I, Chapotera GK, McKew S, van den Broek N. Maternal mortality in sub-Saharan Africa: The contribution of ineffective blood transfusion services. Br J Obstset Gynaecol 2008;115(11):1331-1339. DOI:10.1111/j.1471-0528.2008.01866.x

2. Homer C, Clements V, McDonnell N, Peek M, Sullivan F. Mar Cullivan E. Maternal moraly: What can we learn from stories of 104. DOI:10.1016/j.wombi.2009.02.002

3. National Committee for Confidential Enquiry into Maternal Deaths. Saving Mothers 2011 - 2013: Sixth Report on the Confidential Enquiries into Maternal Deaths in South Africa. Pretoria: South African National Department of Health, 2015.

4. Kon ZR, Lackan N. Ethnic disparities in access to care in postapartheid South Africa. Am J Public Health 2008;98(12):2272-2277. DOI:10.2105/ajph.2007.127829

5. McLaren ZM, Ardington C, Leibbrandt M. Distance decay and persistent health care disparities in South Africa. BMC Health Services Res 2014;14(1):762-776. DOI:10.1186/s12913-014-0541-1

6. Gandhi MN, Welz T, Ronsmans C. Severe acute maternal morbidity in rural South Africa. Int J Gynaecol Obstet 2004:87(2):180-187. 7. Fawcus SR, van Coeverden de Groot HA, Isaacs S. A 50-year audit 7 of maternal mortality in the Peninsula Maternal and Neonatal Service, Cape Town (1953 - 2002). Br J Obstset Gynaecol
2005;112(9):1257-1263.

8. Bates I, Chapotera GK, McKew S, van den Broek N. Maternal mortality in sub-Saharan Africa: The contribution of ineffective blood transfusion services. Br J Obstset Gynaecol 2008;115(11):1331-1339. DOI:10.1111/j.1471-0528.2008.01866.x

9. Fawcus S, Moodley J, for the National Committee for Confidential Enquiry into Maternal Deaths. A Monograph of the Management of Postpartum Haemorrhage. Pretoria: South African National Department of Health, 2010.

10. National Department of Health. The 2011 National Antenatal Sentinel HIV and Syphilis Prevalence Survey in South Africa. Pretoria: $\mathrm{NDoH}, 2012$

11. Bloch EM, Crookes RL, Hull J, et al. The impact of human immunodeficiency virus infection on obstetric hemorrhage and immunodeficiency virus infection on obstetric hemorrhage and
blood transfusion in South Africa. Transfusion 2015;55(7):16751684. DOI: $10.1111 /$ trf. 13040

12. Callaghan WM, Kuklina EV, Berg CJ. Trends in postpartum hemorrhage: United States, 1994 - 2006. Am J Obstet Gynecol 2010;202(4):e351-e356. DOI:310.1016/j.ajog.2010.1001.1011 
13. Bateman BT, Berman MF, Riley LE, Leffert LR. The epidemiology of postpartum hemorrhage in a large, nationwide sample of deliveries. Anesth Analg 2010;110(5):1368-1373. DOI:10.1213/ ANE.0b013e3181d74898

14. Anorlu RI, Orakwe CO, Abudu OO, Akanmu AS. Uses and misuse of blood transfusion in obstetrics in Lagos, Nigeria. West Afr J Med 2003;22(2):124-127.

15. National Maternity Guidelines Committee. Guidelines for Maternity Care in South Africa. Pretoria: South African National Department of Health, 2015

16. Prick BW, Jansen AJG, Steegers EAP, et al. Transfusion policy after severe postpartum haemorrhage: A randomised non-inferiority trial. Br J Obstset Gynaecol 2014;121(8):1005-1014. DOI:10.1111/14710528.12531
17. Kramer MS, Berg C, Abenhaim $\mathrm{H}$, et al. Incidence, risk factors, and temporal trends in severe postpartum hemorrhage. Am J Obstet Gynecol 2013;209(5):e441-e447. DOI:10.1016/j.ajog.2013.07.007

18. Talip Q, Theron G, Steyn W, Hall D. Total perinatally related losses at Tygerberg Hospital - a comparison between 1986, 1993 and 2006. S Afr Med J 2010;100(4):250-253.

19. Calvert C, Ronsmans C. HIV and the risk of direct obstetric complications: A systematic review and meta-analysis. P loS ONE 2013;8(10):e74848. DOI:10.1371/journal.pone.0074848

Accepted 13 May 2016. 